\title{
Event-Related Brain Potentials Depict Cognitive Disturbances in Children with Mild Traumatic Brain Injury
}

\author{
Andrés A. González-Garrido ${ }^{1,2}$, José M. González-González², Fabiola R. Gómez-Velázquez ${ }^{1}$, Teresita \\ Villaseñor $^{2}$, Angélica Flores-Barrios ${ }^{3} \&$ Leonardo E. Aguirre-Portillo ${ }^{2}$ \\ ${ }^{1}$ Instituto de Neurociencias. Universidad de Guadalajara, Mexico \\ ${ }^{2}$ Antiguo Hospital Civil "Fray Antonio Alcalde", Guadalajara, Mexico \\ ${ }^{3}$ Universidad de Sevilla, Spain \\ Correspondence: Andrés A. González-Garrido, Instituto de Neurociencias, Universidad de Guadalajara, Jalisco, \\ Mexico. Tel: 52-333-818-0740. E-mail: gonzalezgarrido@gmail.com
}

Received: September 5, 2013

doi:10.5539/ijps.v5n4p38
Accepted: September 22, $2013 \quad$ Online Published: November 5, 2013

URL: http://dx.doi.org/10.5539/ijps.v5n4p38

\begin{abstract}
Mild traumatic brain injury (MTBI) is a common cause of short-term cognitive disturbances in children that rarely are related to objective neurophysiological markers. With the aim of correlating cognitive processing with event-related brain potential variation, visual Continuous Performance Tests (CPT) were administered to 15 children with MTBI and a matched control group. All the patients had suffered post-traumatic loss of consciousness lasting less than 15 minutes, and they were evaluated within 5-to-15 days post-trauma. A few additional neuropsychological tests were also administered to both groups. Behavioral results showed that the injured children achieved poorer scores for phonological and verbal fluency tasks and no interference effect in a computerized version of the Stroop test. They had fewer correct responses on CPT-AX, where a warning signal preceded targets. The N90, P240 and P390 ERP components varied significantly between groups while performing CPT-AX. Present findings could be interpreted as reflecting disturbances that impede injured children from using contextual information efficiently. The higher amplitude of the slow late positivity observed in the control group might reflect updating memory preparatory processes that could increase subsequent cognitive operational competence. The ERP assessment could be helpful to demonstrate early neurophysiological disturbances subsequent to a MTBI in children.
\end{abstract}

Keywords: brain trauma, cognition, children, ERP, CPT

\section{Introduction}

Traumatic brain injury (TBI) is widely recognized as a major cause of disability in the pediatric population. In particular, mild TBI (MTBI) is one of only a few medical disorders in which a benign misleading diagnosis obtained at the time of injury can be related to future long-term complications.

The clinical criteria for classifying TBI have been revised on various occasions by different authors (Davis, Mullen, Makela, Taylor, Cohen, \& Rivara, 1994; Goldberg et al., 2011; Howard \& Shapiro, 2011) and a variety of organizations, including the American Congress of Rehabilitation Medicine (1993). The latter defined MTBI as a head injury that might include loss of consciousness lasting less than 30 minutes, loss of memory, or altered mental states around the time of the accident (24 hours), and/or transient or intransient focal neurological deficit with a Glasgow Coma Scale ranging from 13-to-15 points.

TBI in children may disrupt the subsequent development of new abilities and alter previously developed ones because vulnerability to brain injury in childhood can affect maturational processes which might lead to deficits in cognitive development (Giza \& Prins, 2006). The sequelae subsequent to a MTBI in childhood could include cognitive and somatic symptoms, as well as emotional and behavioral difficulties affecting academic, behavioral, and interpersonal functioning. Cognitive sequelae may include problems in such areas as: attention, the speed of cognitive and working memory processing, response inhibition, calculation, verbal learning, episodic memory, visuomotor speed, reading, executive functioning and visual delayed recognition (McAllister, Sparling, Flashman, Guerin, Mamourian, \& Saykin, 2001; Levin et al., 2008; Babikian \& Asarnow, 2009; Krivitzky, Roebuck-Spencer, Roth, Blackstone, Johnson, \& Gioia, 2011). It has been determined that somatic and emotional symptoms including fatigue, headache, dizziness, sensitivity to light and noise, irritability, behavioral disinhibition, increased anxiety 
and depression might also be related to TBI (Kirkwood, Yeates, Taylor, Randolph, McCrea, \& Anderson, 2008; Ayr, Yeates, Taylor, \& Browne, 2009; Konrad et al., 2010; Howard \& Shapiro, 2011; Anderson, Godfreya, Rosenfeldd, \& Catroppaa, 2012). Furthermore, children with MTBI are more likely to develop attention deficit/hyperactivity disorder, conduct disorder/oppositional defiant disorder, substance abuse, and mood disorders (McKinlay, Grace, Horwood, Fergusson, \& MacFarlane, 2009).

Despite the fact that the early appearance of different symptoms has been associated with later neurobehavioral and cognitive problems, there is a lack of objective neurophysiological markers to follow up on, and support, clinically based early predictions with respect to children who have suffered a MTBI.

Event-related brain potentials (ERP) have proven to be useful in the study of time-locked cerebral processes while performing behavioral tasks that entail certain attentional and working memory demands. Specifically, the P300 component has been extensively studied as an index of updating memory representations (Polich, 2007; Donchin \& Coles, 1988) and general cognitive performance used to monitor illness evolution in different clinical models (Sumiyoshi et al., 2006; Madan, Kalra, Agarwal, \& Tandon, 2007; Kalita, Misra, \& Srivastava, 2009; Lori et al., 2011; see Duncan et al., 2009 for a review). Furthermore, several reports have indicated that ERP can be applied as a useful supplement to neuropsychological assessments and diagnoses in TBI patients (Lavoie, Dupuis, Johnston, Leclerc, \& Lassonde, 2004; Gosselin, Theriault, Leclerc, Montplaisir, \& Lassonde, 2006; De Beaumont et al., 2009; Dockree \& Robertson, 2011; Duncan, Summers, Perla, Coburn, \& Mirsky, 2011; Folmer, Billings, Diedesch-Rouse, Gallun, \& Lew, 2011; Gosselin et al., 2011; Perlstein \& Larson, 2011; Baillargeon, Lassonde, Leclerc, \& Ellemberg, 2012).

The P300 waveform is usually elicited in odd-ball paradigms. One of the most commonly used odd-ball, go-no go paradigms is the Continuous Performance Test (CPT), which has often been administered to evaluate sustained attention and working memory processing resources (González-Garrido, Gómez-Velázquez, Fernández-Harmony, Oropeza, \& Ruiz-Sandoval, 2001; Straube, Bischoff, Nisch, Sauer, \& Volz, 2002; Suchan, Pickenhagen, \& Daum, 2005; Moustafa, Sherman, \& Frank, 2008).

This study examined the ERP associated with CPT tasks performed by children who had recently suffered a MTBI $v s$. a control group. The main aim of the research was to comparatively evaluate the electrophysiological correlates -with particular emphasis on the P300 component- underlying attention and working memory processing, in order to elucidate whether it would be possible to associate TBI-induced ERP changes with potential behavioral deficits that could be followed-up over time in these patients.

\section{Methods}

\subsection{Subjects}

Fifteen male children, who had recently been evaluated at the emergency service of the "Antiguo Hospital Civil de Guadalajara" due to MTBI, participated voluntarily in the experiment. Parents reported the occurrence of a post-traumatic loss of consciousness lasting less than 15 minutes, though patients had been symptom-free for the 72 hours subsequent to receiving a blow to the head (Glasgow Coma scale scores $\geq 14$ points), and both computed tomography scans and neurological clinical evaluations were normal.

Table 1 summarizes the demographic information of the MTBI patients. All subjects were right-handed with normal IQs (WISC-RM > 95 points; mean=101.1, $\mathrm{SD}=7.4$ ). Age ranged from 8-to-13 years (mean=10.53, $\mathrm{SD}=1.88$ years). They all attended regular primary or secondary school and had normal or corrected-to-normal vision. No antecedents of psychopathology, epilepsy, previous traumatic brain injury, or use of illicit drugs among subjects or their immediate family members (within 24 hours prior to testing) were found during clinical interviews. 
Table 1. Demographic data for participants with mild traumatic brain injury

\begin{tabular}{|c|c|c|c|c|c|c|c|}
\hline Subject & Age (years) & $\begin{array}{c}\text { Time since } \\
\text { injury (hours) }\end{array}$ & Activity & $\begin{array}{l}\text { Cause of } \\
\text { injury }\end{array}$ & $\begin{array}{c}\text { Loss of } \\
\text { Consciousness }\end{array}$ & $\begin{array}{c}\text { Time out of } \\
\text { Consciousness }\end{array}$ & $\begin{array}{c}\text { Glasgow scale } \\
\text { rate } \\
\text { (admission) }\end{array}$ \\
\hline 1 & 9.41 & 126 & Horse riding & Fall & Yes & Seconds & 15 \\
\hline 2 & 13.80 & 131 & $\begin{array}{l}\text { Motorcycle riding } \\
\text { (as passenger) }\end{array}$ & Fall & Yes & 10-12 minutes & 14 \\
\hline 3 & 9.60 & 146 & Tree Climbing & Fall & Yes & $\begin{array}{l}\text { Less than } 10 \\
\text { minutes }\end{array}$ & 14 \\
\hline 4 & 9.40 & 162 & Car crash & $\begin{array}{l}\text { Head to } \\
\text { Roof }\end{array}$ & Yes & 3-5 minutes & 14 \\
\hline 5 & 12.28 & 156 & Cycle Riding & Fall & Yes & Seconds & 15 \\
\hline 6 & 8.76 & 278 & Playing ( $2^{\text {nd }}$ floor $)$ & Fall & Yes & $10-15$ minutes & 14 \\
\hline 7 & 8.67 & 244 & $\begin{array}{l}\text { Playing (behind } \\
\text { horse) }\end{array}$ & $\begin{array}{l}\text { Leg to } \\
\text { Head }\end{array}$ & Yes & $\begin{array}{l}\text { Less than } 10 \\
\text { minutes }\end{array}$ & 14 \\
\hline 8 & 9.48 & 170 & $\begin{array}{l}\text { Playing } \\
\text { (garden-shed) }\end{array}$ & $\begin{array}{l}\text { Hit by } \\
\text { spade }\end{array}$ & Yes & Seconds & 15 \\
\hline 9 & 11.19 & 206 & $\begin{array}{l}\text { Playing (football } \\
\text { soccer) }\end{array}$ & Fall & Yes & Seconds & 15 \\
\hline 10 & 11.56 & 160 & ATV driving & $\begin{array}{l}\text { Hit a } \\
\text { horse }\end{array}$ & Yes & About 10 minutes & 14 \\
\hline 11 & 13.04 & 246 & Running & Fall & Yes & Seconds & 15 \\
\hline 12 & 13.05 & 384 & ATV driving & Fall & Yes & $\begin{array}{l}\text { Less than } 10 \\
\text { minutes }\end{array}$ & 14 \\
\hline 13 & 13.13 & 245 & $\begin{array}{l}\text { Playing at Inflatable } \\
\text { jumper }\end{array}$ & Fall & Yes & Seconds & 15 \\
\hline 14 & 8.36 & 176 & Street Crossing & Hit by car & Yes & Seconds & 15 \\
\hline 15 & 10.65 & 152 & Running & Fall & Yes & Seconds & 15 \\
\hline
\end{tabular}

An additional group of 15 healthy male, right handed children volunteered to participate as controls, and were matched with patients by age (mean=10.01, SD=1.96 years), socio-economic level (within the middle class framework, FESETS, 2010) and school grade. All the control children had IQs scores above 95 points (mean=103.9, $\mathrm{SD}=6.2$ ), showing no significant differences with the group of patients with respect to this variable. Ethical approval for all procedures was obtained prior to the study. Informed written consent was also obtained from parents, and all children assented.

\subsection{Design and Procedure}

\subsubsection{Behavioral Data and Experimental Task}

Two go-no go CPT tasks were presented using Mind-Tracer software (Neuronic, S.A.). In the first task (no warning: NW), participants were instructed to press a key on a computer keyboard with their right index finger as soon as possible after a randomized, infrequent (20/80) target letter $(X)$ appeared on the screen. For the second task (with warning: WW), subjects were instructed to press the same key as before, also as soon as possible, upon the presentation of the target letter (X), but only if it was preceded by another specific letter, in this case A. But the letter A could also precede three other letters $(\mathrm{E}, \mathrm{C}, \mathrm{T})$, which were used as complementary stimuli. The pair 'warning-target letters' (A-X) represented $20 \%$ of total stimuli.

Participants were seated comfortably in a quiet, dimly-lit room. Visual stimuli were presented on an ACER 17" flat panel monitor -82945G Express Chip Set Family- using 1024 x 768 pixel resolution. All stimuli were presented sequentially and automatically during $500 \mathrm{~ms}$ (stimulus duration) with an inter-stimuli interval of $1500 \mathrm{~ms}$, at a visual display angle of $0.70^{\circ}$. The stimuli were centrally projected in white upper-case Arial 90 letters against a 
black background. Reaction times (RTs) and behavioral responses were measured and evaluated by software in all trials.

\subsubsection{Additional Neuropsychological Tests}

Working memory span was assessed using the backward digit-span task (Wechsler, 1997). The speed and ease of verbal production was tested through semantic and phonological verbal fluency tasks. Participants also completed a 4-min computerized version of the Stroop task administered with Mindtracer (Neuronic S.A.) software to measure selective attention, cognitive flexibility and processing speed (Ozen \& Fernandes, 2012). In this particular task, they were informed that a string of lower-case letters ("red", "blue" or "green"; presented in Calibri font, with 20 point size) would appear one at a time on the computer screen, and instructed to press the " $\leftarrow$ " key if the font color was red, " $\uparrow "$ key if the font color was blue, and the " $\rightarrow$ " key if the font was green (counterbalanced). The task consisted of 84 incongruent trials (i.e., the word "green" in blue-color font) equally divided into two blocks. In the first block, children had to respond in accordance with the meaning of the word (Word), while in the second they responded in reference to the color of the font (Color). Participants' accuracy and response time in each condition were recorded.

\subsubsection{ERP Acquisition}

ERPs were recorded in all conditions from $100 \mathrm{~ms}$ before the onset of the stimuli until $1000 \mathrm{~ms}$ after stimuli presentation. ERP were recorded from the F3, F4, C3, C4, P3, P4, O1, O2, Fz, Cz, and Pz scalp electrode sites, according to the 10-20 system. An electrooculogram (EOG) was recorded from the outer canthus and infraocular orbital ridge of the right eye. Electrophysiological recordings were made using $10 \mathrm{~mm} \mathrm{Ag} / \mathrm{AgCl}$ electrodes. All recording sites were referred to linked mastoids. Interelectrode impedances were below $5 \mathrm{k} \Omega$. EEG and EOG signals were amplified at a bandpass of $0.5-30 \mathrm{~Hz}$ (3-dB cutoff points of $6 \mathrm{~dB} /$ octave roll-off), with a sampling period of $5 \mathrm{~ms}$ on the MEDICID-04 system. Single trial data were then examined off-line for averaging and analysis.

Epochs of data from all channels were excluded from averages when the voltage in a given recording epoch exceeded $100 \mu \mathrm{V}$ on any EEG or EOG channel. At least 20 correct, artifact-free trials were obtained from each condition and participant to yield a signal-noise ratio higher than 1.5. Amplitude and latency for the ERP components were measured according to a $100 \mathrm{~ms}$ pre-stimulus baseline. All scoring was conducted baseline-to-peak through visual inspection.

\subsubsection{Data Analysis}

Independent sample t-tests (including Bonferroni corrections) were applied to the behavioral data. For the purposes of this study, the appearance of the stimulus was taken as the initial time instant ( $\mathrm{t} 0)$ and twenty time windows were used to contrast the averaged ERP waveforms. Electrophysiological measures were assessed using Randomized-block ANOVAs [group (2) $\times$ condition (2: target, non-target) x recording site (7)] with maximum voltage across each time window. The amplitude and latency of each ERP component were quantified by the highest peak within each respective latency window. Greenhouse-Geisser corrections to the df were applied as needed, with the corrected probabilities reported. Post-hoc Tukey's HSD tests were used to explore any trends in the differences found.

Pearson correlation coefficients were calculated for the entire sample to evaluate the relationship between behavioral performance on the CPT and the additional neuropsychological tasks, with respect to significant electrophysiological measures.

\section{Results}

\subsection{Behavioral Results}

The Stroop test results showed that the interference effect was restricted to the participants in the control group, who were slower and less accurate when they had to respond according to the color of the font in which the words appeared, as compared to the condition in which they responded in reference to the literal meaning of the word. The MTBI children did not exhibit substantial differences between conditions; nonetheless, this group was significantly slower and less accurate than controls in the "Word" condition. Table 2 shows the performance of both groups in the psychological tasks, except for the CPTs.

The evaluation of semantic verbal fluency and phonological verbal fluency showed significantly higher scores for the control group. While performing the backward digit span test, control children showed a tendency to obtain better scores than the mild-TBI group, however statistical significance was not achieved. See Table 2. 
Table 2. Behavioral performances from both groups in different psychological tasks

\begin{tabular}{lcccccc}
\hline \multicolumn{1}{c}{ Tests } & \multicolumn{7}{c}{ Control Group } & \multicolumn{2}{c}{ MTBI Group } & & \\
& Mean & SD & Mean & SD & t & $\mathbf{p ( t )}$ \\
\hline Stroop Word & & & & & & \\
$\quad$ Correct Responses & 37.2 & 5.3 & 32.7 & 6.8 & 2.010 & 0.055 \\
$\quad$ Reaction Times & 855.2 & 151.9 & 1003.4 & 171.1 & -2.510 & $\mathbf{0 . 0 1 8}$ \\
$\quad$ Stroop Color & & & & & & \\
$\quad$ Correct Responses & 34.9 & 4.9 & 33.0 & 5.9 & 0.968 & 0.341 \\
$\quad$ Reaction Times & 876.2 & 150.9 & 1032.7 & 537.4 & -1.086 & 0.293 \\
$\quad \begin{array}{l}\text { Semantic Verbal Fluency } \\
\text { Phonological Verbal }\end{array}$ & 15.4 & 4.4 & 11.6 & 3.3 & 2.677 & $\mathbf{0 . 0 1 3}$ \\
$\quad$ Fluency & 6.8 & 3.7 & 3.0 & 2.4 & 3.361 & $\mathbf{0 . 0 0 3}$ \\
Backward Digit Span & 4.2 & 0.7 & 3.5 & 1.1 & 1.967 & 0.061 \\
\hline
\end{tabular}

SD: standard deviation; t: Student' t tests; $\mathbf{p}$ : probability

Behavioral performance on the experimental tasks is shown in Table 3. In general, there were only non-significant differences between the groups while performing the CPT-X task, but controls showed a significantly higher number of correct responses $\left(t_{(1,14)}=3.53, p<0.01\right)$ than those reached by the mild TBI patients.

Table 3. Behavioral responses from both groups while performing the experimental tasks.

\begin{tabular}{llcccc}
\hline Tests & & $\begin{array}{c}\text { Control } \\
\text { Group }\end{array}$ & MTBI Group & t & p(t) \\
\hline CPT-X & Correct Responses & $38.3(1.7)$ & $37.2(5.9)$ & 0.644 & 0.525 \\
& Incorrect Responses & $1.7(2.1)$ & $3.1(2.1)$ & -1.702 & 0.101 \\
& No Responses & $1.9(1.7)$ & $2.8(5.9)$ & -0.558 & 0.582 \\
& Reaction Times & $514.4(64.6)$ & $525.3(73.8)$ & -0.416 & 0.681 \\
CPT-AX & Correct Responses & $28.7(1.3)$ & $25.6(3.1)$ & 3.530 & $<\mathbf{0 . 0 1}$ \\
& Incorrect Responses & $1.9(2.2)$ & $2.7(2.6)$ & -0.930 & 0.361 \\
& No Responses & $1.3(1.3)$ & $4.5(3.0)$ & -3.634 & $<\mathbf{0 . 0 1}$ \\
& Reaction Times & $433.5(60.6)$ & $471.9(78.5)$ & -1.453 & 0.158 \\
\hline
\end{tabular}

Mean (Standard deviation), $\mathbf{t}$ : $\mathrm{t}$ value

\subsection{Electrophysiological Results}

\subsubsection{CPT-X}

Fig. 1 illustrates the mean voltage amplitude for midline event-related brain potentials while performing both experimental tasks. Regarding latency and polarity, the ERP recorded during performance of the CPT-X task in the control group showed a sequence -at parietal sites- of four main components, depending on condition: i.e., N120, P240, N350 and P450, respectively. According to visual inspection, differences between conditions were restricted to the P240 (TBI) and P450 (controls) waveforms. Therefore, two time windows were selected to comparatively evaluate the ERP waveforms on the CPT-X task: 150-300, and 300-600 ms, respectively, using the electrode locations that showed the clearest differences (C3, C4, P3, P4, Fz, Cz and Pz). 

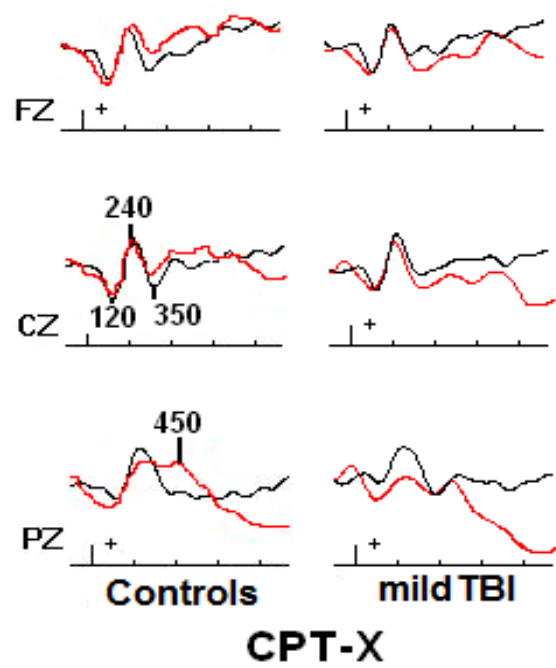
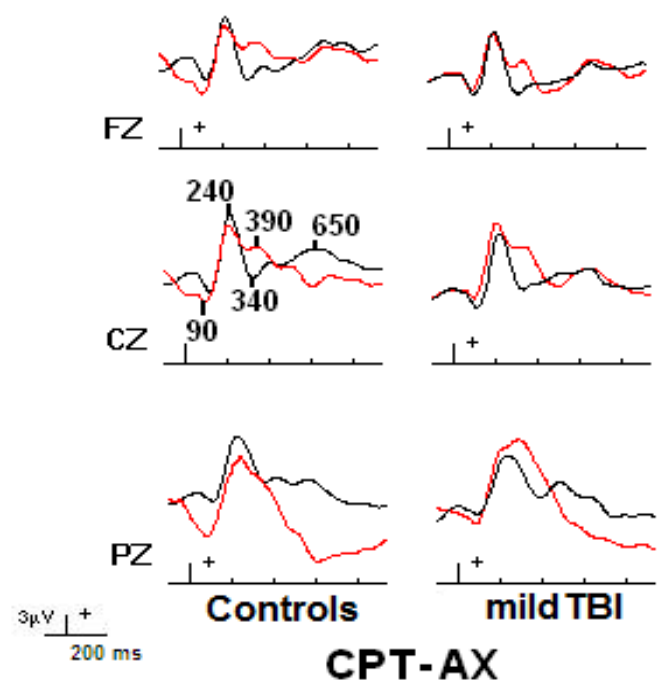

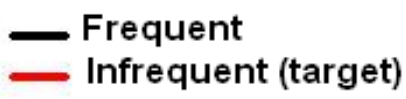

Figure 1. Midline grand-averaged event-related brain potentials while performing both experimental tasks

Randomized-block ANOVAs for the first time window (P240) showed relevant differences between groups for the factor of recording site $(\mathrm{F}(6,168)=3.30, \mathrm{p}<0.01)$ and for the interaction of condition x recording site $(\mathrm{F}(6,168)=3.56$, $\mathrm{p}<0.01)$. Pearson correlation analysis showed that slower response times while performing the Stroop "Color" condition correlated with lower voltage amplitudes in $\mathrm{Cz}$ and $\mathrm{Pz}(\mathrm{r}=-0.373, \mathrm{p}<0.05$ and $\mathrm{r}=-0.421, \mathrm{p}<0.05$, respectively) during non-target ERP trials.

Although differences between groups did not reach statistical significance, the analysis of P450 showed a tendency to differentiate the factor group $\left.\left(\mathrm{F}_{1,168}\right)=3.57, \mathrm{p}=0.06\right)$, and interaction of group $\mathrm{x}$ condition $\left(\mathrm{F}\left({ }_{1,168}\right)=3.0, \mathrm{p}=0.08\right)$, reflecting a clear tendency for subtle target-non-target voltage differences to appear. In addition, higher numbers of correct responses correlated with higher amplitudes in $\mathrm{F} 3(\mathrm{r}=0.387, \mathrm{p}<0.05)$, and when performing non-target trials, higher number of recalled digits in the backward digit span test correlated with higher amplitudes in F3, F4, and Fz ( $\mathrm{r}=0.367, \mathrm{p}<0.05 ; \mathrm{r}=-0.422, \mathrm{p}<0.05$, and $\mathrm{r}=0.398, \mathrm{p}<0.05$, respectively).

\subsubsection{CPT-AX}

During performance of CPT-AX, ERP morphology was similar to that described for CPT-X. Regarding their temporal appearance and polarity, ERP in the control group could be described generally as a sequence of N90, P240, N340 and P390 main components, followed by a slow late positivity (SLP) over the central-anterior region that apparently reached its highest voltage over $650 \mathrm{~ms}$ (see Figure 1). Consequently, four time windows were designed to analyze ERP variations: N90 (0-150), P240 (150-300), N340-P390 (300-500) and SLP (500-1000) ms, respectively. Based upon visual analysis, the main voltage changes seemed to be more frontally distributed; therefore ERP results were analyzed at locations F3, F4, P3, P4, Fz, Cz and Pz.

The analysis of N90 showed significant interactions between group and recording site $(F(6,168)=6.21, p<0.001)$, condition and recording site $\left.\left(\mathrm{F}_{6,168}\right)=4.06, \mathrm{p}<0.001\right)$, and among the three factors of group, condition and recording site $\left.\left(\mathrm{F}_{6,168}\right)=3.15, \mathrm{p}<0.01\right)$. The post-hoc analysis basically showed that fronto-central locations reached significantly higher negative amplitudes in the control group [Fz: $(\mathrm{p}<0.05)]$. Furthermore, target trials showed more negative voltage amplitudes [F3: $(p<0.01)$; Fz: $(p<0.05)$; Cz: $(p<0.05)$; Pz: $(p<0.05)$ ]. Finally, this triple interaction strengthens the notion that N90 was significantly higher during target trials in the control group [Pz: $(p<0.05)]$.

The analysis of $\mathrm{P} 240$ showed a relevant triple interaction effect $(\mathrm{F}(6,168)=2.39, \mathrm{p}<0.05)$ in which post-hoc analysis emphasized that during this time window mild TBI children reached higher voltages over the parietal regions in target $v s$. non-target conditions [C4 $(\mathrm{p}<0.05)]$. The correlation analysis showed that higher amplitudes of $\mathrm{P} 240$ over F4 $(r=0.50, p<0.05), C 3(r=0.45, p<0.05), C 4(r=0.424, p<0.05), F z(r=0.416, p<0.05), C z(r=0.444, p<0.05)$ and Pz $(\mathrm{r}=0.417, \mathrm{p}<0.05)$ correlated positively with higher reaction times during task performance. In addition, slower response times while performing the Stroop "Word" condition correlated with higher amplitudes in F3 ( $\mathrm{r}=0.509$, $\mathrm{p}<0.01), \mathrm{F} 4(\mathrm{r}=0.519, \mathrm{p}<0.01), \mathrm{C} 3(\mathrm{r}=0.404, \mathrm{p}<0.05), \mathrm{C} 4(\mathrm{r}=0.427, \mathrm{p}<0.05), \mathrm{Fz}(\mathrm{r}=0.534, \mathrm{p}<0.05)$, and $\mathrm{Cz}(\mathrm{r}=0.382$, 
$\mathrm{p}<0.05)$. Moreover, when performing the "Color" condition, slower response times correlated with higher voltages in $\mathrm{F} 3(\mathrm{r}=0.371, \mathrm{p}<0.05)$, and $\mathrm{C} 4(\mathrm{r}=0.377, \mathrm{p}<0.05)$.

In the third time window (N340-P390), visual inspection of ERP showed that there was a positive waveform peaking at $390 \mathrm{~ms}$ over the central parietal regions when target trials were processed. Statistical analysis revealed a significant interaction between group and recording site $(\mathrm{F}(6,168)=2.83, \mathrm{p}<0.05)$, and post-hoc tests demonstrated that ERP from the mild TBI group reached higher voltages over the posterior parietal region $(\mathrm{p}<0.05)$. Correlation analysis showed that higher numbers of correct responses while performing CPT-AX correlated with higher voltages of $\mathrm{P} 390$ over $\mathrm{C} 3(\mathrm{r}=0.384, \mathrm{p}<0.05), \mathrm{C} 4(\mathrm{r}=0.408, \mathrm{p}<0.05)$ and $\mathrm{Cz}(\mathrm{r}=0.461, \mathrm{p}<0.05)$.

Finally, the analysis of SLP demonstrated that the interactions of group $x$ condition $(F(6,168)=10.67, p<0.01)$ and group $\mathrm{x}$ condition $\mathrm{x}$ recording site $(\mathrm{F}(6,168)=5.50, \mathrm{p}<0.001)$ were both highly significant. Post-hoc comparisons showed that during the processing of non-target trials SLP was significantly higher in the control group $(\mathrm{p}<0.01)$. Furthermore, this triple interaction demonstrated that voltage differences were particularly significant over $\mathrm{F} 4$ $(p<0.01), C 3(p<0.01)$ and C4 $(p<0.01)$. The amplitude of SLP negatively correlated with response times while performing target condition $(\mathrm{r}=-0.444, \mathrm{p}<0.05)$. In addition, a higher number of correct responses while performing the Stroop "Word" condition correlated with higher amplitudes in F4 $(r=0.510, p<0.01), C 4(r=0.390, p<0.05)$ and $\mathrm{Fz}(\mathrm{r}=0.404, \mathrm{p}<0.05)$.

\section{Discussion}

One of the main purposes of the present study was to comparatively evaluate the consequences of a MTBI on cognitive processing, more specifically on attention and working memory dependent-mechanisms in school attending children, through an ERP design performed within the first few days post-trauma. In this case, most of the traumatized children had suffered a very short loss of consciousness but manifested no additional complications upon admission to the emergency service, and were discharged no more than 24 hours later, due to the absence of clinical symptoms and the normal results of both neuroimaging and clinical neurological evaluations.

In general, the impact of traumatic brain injury on individual performance and the increased vulnerability in childhood have been very well documented. However, it remains unclear whether early effects could be prolonged in the long term, particularly in cases of mild injuries. Due to the difficulties involved in doing follow-up into adolescence and adulthood on children who had suffered mild TBI, few studies have pursued this objective. Thus, overall, only few long-term neurobehavioral consequences have been associated with MTBI (McKinlay, Dalrymple-Alford, Horwood, \& Fergusson, 2002; Hessen, Nestvold, \& Anderson, 2007; Anderson, et al., 2012).

Recently, a substantial pool of patients was evaluated 10 years after traumatic brain injury episodes. The main finding of that study was a significant impairment of adaptive abilities and processing speed (Anderson et al., 2012). However, adaptive abilities are intrinsically difficult to evaluate in terms of their clinical evolution because they could represent the outcome of the interaction of numerous clinical and environmental variables. Therefore, on the basis of the aforementioned results, one could predict that processing speed might be significantly affected in the present study, as it is difficult to assume that this parameter would deteriorate with time.

In fact, MTBI children were significantly slower than controls when classifying stimuli according to their meaning while performing the Stroop task. This result is also in line with other studies which have reported slower processing speeds on standard neuropsychological tests in the post-acute phase following one mild TBI (Solbakk, Reinvang, Neilsen, \& Sundet, 1999; Bernstein, 2002; Potter, Jory, Bassett, Barrett, \& Mychalkiw, 2002). Nevertheless, the MTBI group did not show the classic interference effect observed in the control group. As the Stroop task requires interference control, -usually understood as the ability to perform an act while ignoring distracting, competing, or conflicting information (Sinopoli \& Dennis, 2012)- the present results seem to point out that during this early clinical period, MTBI children could also suffer problems with their inhibitory control. The significant differences observed between the two groups while performing semantic and phonological verbal fluency tasks might support the assumption of a temporary disturbance to mental processes requiring further attention and working memory resources.

On the other hand, there were no significant statistical differences between the groups with respect to the speed with which they performed the experimental tasks; however, the MTBI children had lower scores and higher voltage magnitudes for P3-like and earlier ERP components while performing the more demanding task (i.e., CPT-AX). Moreover, correlation analysis ratified these findings by showing significant relationships between RTs -while performing CPT-AX- and the amplitude of P300.

Considering the odd-ball experimental design used, electrophysiological results could be interpreted using the classical P3 framework. Although statistical significance was not reached in the ERP analysis during CPT-X 
performance, it became relatively clear that the posterior voltage magnitude of the P200-like component was lower in the mild-TBI group, while control children showed a greater P300 component. The lack of significant effects could be due to individual data variability, perhaps explained by the age of the participants which directly suggests different levels of neural maturation (Shaw et al., 2008; Kurth, Ringli, Geiger, LeBourgeois, Jenni, \& Huber, 2010; Rubia, Hyde, Halari, Giampietro, \& Smith, 2010; Barkat, Polley, \& Hensch, 2011).

Several ERP components varied significantly between the two groups while performing the CPT-AX task. Foremost, N90 was clearly greater among controls. Regarding the fact that a warning signal had to precede the appearance of target letters, N90 -due to its early emergence- must be interpreted as reflecting the effect of the warning signal, one that could be related to the conception and maintenance of a visual template of the expected subsequent target letter, or reflect an early rough visual comparison between the appearing target and its anticipated mental template. Also, it could be the reflection of a contingent negative variation triggered by the warning signal itself. Earlier reports seem to offer support for any one of these notions (Strandburg et al., 1996; González-Garrido et al., 2001). Whatever the theoretical alternative might be, they all do seem to point to the probable failure of the injured children to efficiently use relevant contextual information.

Interestingly, the P200-like component showed higher amplitudes during the target condition in the MTBI children. If we consider that P200 reflects visual spatial attention orientation (Di Russo et al., 2012; Kanske, Plitschka, \& Kotz, 2011) and/or working memory encoding-context updating processes (Lenartowicz, Escobedo-Quiroz, \& Cohen, 2010; Finnigan, O'Connell, Cummins, Broughton, \& Robertson, 2011), then greater amplitudes on this component could be interpreted as an index of a greater cognitive effort in the traumatized children, which mirrored differences between the groups with respect to their behavioral performance. This finding suggests that injured children could require a supplementary recruitment of cognitive resources in order to successfully respond to cognitive demands.

In the odd-ball paradigm the P300 component has been interpreted as the result of an orienting response with attention allocation triggered by novel or unusual stimuli that give rise to an "updating" process of the stimulus representation (see Polich, 2007 for an extensive review). It has been shown that the amplitude of this ERP component is sensitive to numerous variables and conditions, particularly the amount of attentional resources engaged during task performance (Isreal, Chesney, Wickens, \& Donchin, 1980; Kramer, Wickens, \& Donchin, 1985) and memory engagement (Hartikainen \& Knight, 2003; Azizian \& Polich, 2007).

This study found that the P300-like component reached higher amplitudes in the mild-TBI group. Regarding the theoretical view which assumes that incoming stimuli elicit top-down attention switching, while bottom-up memory-drive processes settle on the final outcome (Escera, Alho, Winkler, \& Näätänen, 1998; Goldstein, Spencer, $\&$ Donchin, 2002), our results could depict the need for additional attentional resources to maintain memory items in the injured children, a notion that seems to be supported by their poorer behavioral performance.

Later ERP changes might be related to perceptual closure processes leading to response set-off or, alternatively, with respect to averaged reaction times they might represent part of the preparatory set deployed to deal with the next incoming stimuli. In view of the fact that SLP showed distinctly higher amplitudes for non-targets in the control group, and non-target trials included the letter "A" acting as a warning signal for subsequent trials, one could assume that the non-target SLP might reflect an early memory index that could already depict processing advantages in the control group. Correlation analysis seems to provide additional support for this notion, while showing that children with shorter response times in CPT-AX also showed higher SLP amplitudes.

Finally, it could be important to highlight that most of the children evaluated for a MTBI at emergency services in Mexico receive no subsequent medical or psychological evaluation when they exhibit a fast clinical recovery. Although some authors have suggested that EEG following after a MTBI in children could be unnecessary (Oster, Shamdeen, Gottschling, Gortner, \& Meyer, 2010), this might be due to the lack of specificity of the routine EEG. In fact, the results of the present study suggest that injured children may well require additional examination, and that neuropsychological evaluation and ERP methods combined could be useful to depict and follow-up on long-term potential cognitive deficits.

\section{Conclusion}

Overall, present findings could be interpreted as reflecting disturbances that impede injured children from using contextual information efficiently, probably resulting in the need for recruitment of supplementary cognitive resources to fulfill simple demands. Beyond the behavioral differences observed between MTBI and control children while performing different neuropsychological tasks, several ERP variations distinguished between children with MTBI and controls. Consequently, these findings seem to strengthen the notion that ERP assessment could be helpful to characterize neurophysiological brain disturbances since very early post-traumatic brain injury 
stages. The extensive availability, non-invasiveness and low cost of ERP tools are advantages that facilitate their extensive use in developing countries, with the aim to enrich the clinical follow-up of children who have suffered a mild brain trauma.

\section{Acknowledgements}

The authors are grateful to Dr. Fabiola Fajardo and Dr. Erwin Villuendas for their help in recruiting patients and healthy children and/or for technical support. We would also like to thank the staff of the Emergency Service of the "Antiguo Hospital Civil de Guadalajara".

\section{References}

ACRM [American Congress of Rehabilitation Medicine]. (1993). Definition of mild traumatic brain injury. Developed by the Mild Traumatic Brain Injury Committee of the Head Injury Interdisciplinary Special Interest Group of the American Congress of Rehabilitation Medicine. Journal of Head Trauma Rehabilitation, 8(3), 86-87. http://dx.doi.org/10.1093/arclin/acp006

Anderson, V., Godfreya, C., Rosenfeldd, J. V., \& Catroppaa, C. (2012). 10 years outcome from childhood traumatic brain injury. International Journal of Developmental Neuroscience, 30(3), 217-224. http://dx.doi.org/10.1016/j.ijdevneu.2011.09.008

Ayr, L. K., Yeates, K. O., Taylor, H. G., \& Browne, M. (2009). Dimensions of postconcussive symptoms in children with mild traumatic brain injuries. Journal of the International Neuropsychological Society, 15(1), 19-30. http://dx.doi.org/10.1017/S1355617708090188

Azizian, A., \& Polich, J. (2007). Evidence for attentional gradient in the serial position memory curve from $\begin{array}{llll}\text { ERPs. Journal of } & \text { Cognitive Neuroscience, } & \text { 19(12), }\end{array}$ http://dx.doi.org/10.1162/jocn.2007.19.12.2071

Babikian, T., \& Asarnow, B. (2009). Neurocognitive outcomes and recovery after pediatric TBI: Meta-analytic review of the literature. Neuropsychology, 23(3), 283-296. http://dx.doi.org/10.1037/a0015268

Baillargeon, A., Lassonde, M., Leclerc, S., \& Ellemberg, D. (2012). Neuropsychological and neurophysiological assessment of sport concussion in children, adolescents and adults. Brain Injury, 26(3), 211-220. http://dx.doi.org/10.3109/02699052.2012.654590

Barkat, T. R., Polley, D. B., \& Hensch, T. K. (2011). A critical period for auditory thalamocortical connectivity. Nature Neuroscience, 14(9), 1189-1194. http://dx.doi.org/10.1038/nn.2882

Bernstein, D. M. (2002). Information processing difficulty long after self-reported concussion. Journal of the International Neuropsychological Society, 8(5), 673-682. http://dx.doi.org/10.1017/S1355617702801400

Davis, R. L., Mullen, N., Makela, M., Taylor, J. A., Cohen, W., \& Rivara, F. P. (1994). Cranial computed tomography scans in children after minimal head injury with loss of consciousness. Annals of Emergency Medicine, 24(4), 640-645.

De Beaumont, L., Theoret, H., Mongeon, D., Messier, J., Leclerc, S., Tremblay, S., ... Lassonde, M. (2009). Brain function decline in healthy retired athletes who sustained their last sports concussion in early adulthood. Brain, 132(Pt 3), 695-708. http://dx.doi.org/10.1093/brain/awn347

Di Russo, F., Stella, A., Spitoni, G., Strappini, F., Sdoia, S., Galati, G., ... Pitzalis, S. (2012). Spatiotemporal brain mapping of spatial attention effects on pattern-reversal ERPs. Human Brain Mapping, 33(6), 1334-1351. http://dx.doi.org/10.1002/hbm.21285

Dockree, P. M., \& Robertson, I. H. (2011). Electrophysiological markers of cognitive deficits in traumatic brain $\begin{array}{llll}\text { injury. International Journal of Psychophysiology, } & \text { 82(1), }\end{array}$ http://dx.doi.org/10.1016/j.jpsycho.2011.01.004

Donchin, E., \& Coles, M. G. (1988). Is the P300 component a manifestation of context updating? Behavioral and Brain Science, 11(3), 357-427. http://psycnet.apa.org/doi/10.1017/S0140525X00058027

Duncan, C. C., Barry, R. J., Connolly, J. F., Fischer, C., Michie, P.T., Näätänen, R., ... Van Petten, C. (2009). Event-related potentials in clinical research: Guidelines for eliciting, recording, and quantifying mismatch negativity, P300, and N400. Clinical Neurophysiology, 120(11), 1883-1908. http://dx.doi.org/10.1016/j.clinph.2009.07.045 
Duncan, C. C., Summers, A. C., Perla, E. J., Coburn, K. L., \& Mirsky, A. F. (2011). Evaluation of traumatic brain injury: Brain potentials in diagnosis, function, and prognosis. International Journal of Psychophysiology, 82(1), 24-40. http://dx.doi.org/10.1016/j.ijpsycho.2011.02.013

Escera, C., Alho, K., Winkler, I., \& Näätänen, R. (1998). Neural mechanisms of involuntary attention to acoustic novelty and change. Journal of Cognitive Neuroscience, 10(5), 590-604. http://dx.doi.org/10.1162/089892998562997

Estudio Socioeconómico. (2010). Sistema Estatal de Cuotas de Recuperación. Secretaría de Salud Estado de Jalisco. FESETS 01/05.

Finnigan, S., O'Connell, R. G., Cummins, T. D., Broughton, M., \& Robertson, I. H. (2011). ERP measures indicate both attention and working memory encoding decrements in aging. Psychophysiology, 48(5), 601-611. http://dx.doi.org/10.1111/j.1469-8986.2010.01128.x

Folmer, R. L., Billings, C. J., Diedesch-Rouse, A. C., Gallun, F. J., \& Lew, H. L. (2011). Electrophysiological assessments of cognition and sensory processing in TBI: applications for diagnosis, prognosis and rehabilitation. International Journal of Psychophysiology, $82(1), \quad 4-15$. http://dx.doi.org/10.1016/j.jpsycho.2011.03.005

Giza, C. C., \& Prins, M. L. (2006). Is being plastic fantastic? Mechanisms of altered plasticity after developmental traumatic brain injury. Developmental Neuroscience, 28(4-5), 364-379. http://dx.doi.org/10.1159/000094163

Goldberg, J., McClaine, R. J., Cook, B., Garcia, V. F., Brown, R. L., Crone, K., \& Falcone, R. A. Jr. (2011). Use of a mild traumatic brain injury guideline to reduce inpatient hospital imaging and charges. Journal of Pediatric Surgery, 46(9), 1777-1783. http://dx.doi.org/10.1016/j.jpedsurg.2011.02.052

Goldstein, A., Spencer, K., \& Donchin, E. (2002). The influence of stimulus deviance and novelty on the P300 and novelty P3. Psychophysiology, 39(6), 781-790. http://dx.doi.org/10.1111/1469-8986.3960781

González-Garrido, A. A., Gómez-Velázquez, F. R., Fernández-Harmony, T., Oropeza, J. L., \& Ruiz-Sandoval, J. L. (2001). Event-related brain potentials during a Continuous Performance Test (CPT) task in normal children. Archives of Medical Research, 32(3), 214-220. http://dx.doi.org/10.1016/S0188-4409(01)00273-9

Gosselin, N., Bottari, C., Chen, J. K., Petrides, M., Tinawi, S., de Guise, E., \& Ptito, A. (2011). Electrophysiology and functional MRI in post-acute mild traumatic brain injury. Journal of Neurotrauma, 28(3), 329-341. http://dx.doi.org/10.1089/neu.2010.1493

Gosselin, N., Theriault, M., Leclerc, S., Montplaisir, J., \& Lassonde, M. (2006). Neurophysiological anomalies in symptomatic and asymptomatic concussed athletes. Neurosurgery, 58(6), 1151-1161. doi:10.1227/01.NEU.0000215953.44097.FA

Hartikainen, K., \& Knight, R. T. (2003). Lateral and orbital prefrontal cortex contributions to attention. In J. Polich (Ed.), Detection of change: Event-related potential and fMRI findings (pp. 99-116). Boston: Kluwer Academic Publishers.

Hessen, E., Nestvold, K., \& Anderson, V. (2007). Neuropsychological function 23 years after mild traumatic brain injury: A comparison of outcome after paediatric and adult head injuries. Brain Injury, 21(9), 963-979. http://dx.doi.org/10.1080/02699050701528454

Howard, P. K., \& Shapiro, S. E. (2011). Diagnosing and treating mild traumatic brain injury in children. $\begin{array}{llll}\text { Advanced } \quad \text { Emergency } & \text { Nursery 274-278. }\end{array}$ http://dx.doi.org/10.1097/TME.0b013e318233d43c

Isreal, J. B., Chesney, G. L., Wickens, C. D., \& Donchin, E. (1980). P300 and tracking difficulty: Evidence for multiple resources in dual-task performance. Psychophysiology, 17(3), 259-273. http://dx.doi.org/10.1111/j.1469-8986.1980.tb00146.x

Kalita, J., Misra, U. K., \& Srivastava, A. (2009). Cognitive impairment in encephalitis: P3 and MRI correlation. Electromyography and Clinical Neurophysiology, 49(1), 27-33.

Kanske, P., Plitschka, J., \& Kotz, S. A. (2011). Attentional orienting towards emotion: P2 and N400 ERP effects. Neuropsychologia, 49(11), 3121-3129. http://dx.doi.org/10.1016/j.neuropsychologia.2011.07.022

Kirkwood, M. W., Yeates, K. O., Taylor, H. G., Randolph, C., McCrea, M., \& Anderson, V. A. (2008). Management of pediatric mild traumatic brain injury: A neuropsychological review from injury through recovery. Clinical Neuropsychology, 22(5), 769-800. http://dx.doi.org/10.1080/13854040701543700 
Konrad, C., Geburek, A. J., Rist, F., Blumenroth, H., Fischer, B., Husstedt, I., ...Lohmann, H. (2010). Long-term cognitive and emotional consequences of mild traumatic brain injury. Psychological Medicine, 22, 1-15. http://dx.doi.org/10.1016/j.jad.2010.10.041

Kramer, A. F., Wickens, C. D., \& Donchin, E. (1985). Processing of stimulus properties: evidence for dual-task integrality. Journal of Experimental Psychology: Human Perception and Performance, 11(4), 393-408. http://dx.doi.org/10.1037/0096-1523.11.4.393

Krivitzky, L. S., Roebuck-Spencer, T. M., Roth, R. M., Blackstone, K., Johnson, C. P., \& Gioia, G. (2011). Functional magnetic resonance imaging of working memory and response inhibition in children with Mild Traumatic Brain Injury. Journal of the International Neuropsychological Society, 17(6), 1143-1152. http://dx.doi.org/10.1017/S1355617711001226

Kurth, S., Ringli, M., Geiger, A., LeBourgeois, M., Jenni, O. G., \& Huber, R. (2010). Mapping of cortical activity in the first two decades of life: a high-density sleep electroencephalogram study. Journal of Neuroscience, 30(40), 13211-13219. http://dx.doi.org/10.1523/JNEUROSCI.2532-10.2010

Lavoie, M. E., Dupuis, F., Johnston, K. M., Leclerc, S., \& Lassonde, M. (2004). Visual p300 effects beyond symptoms in concussed college athletes. Journal of Clinical and Experimental Neuropsychology, 26(1), 55-73. http://dx.doi.org/10.1076/jcen.26.1.55.23936

Lenartowicz, A., Escobedo-Quiroz, R., \& Cohen, J. D. (2010). Updating of context in working memory: An event-related potential study. Cognitive, Affective \& Behavioral Neuroscience, 10(2), 298-315. http://dx.doi.org/10.3758/CABN.10.2.298

Levin, H. S., Hanten, G., Roberson, G., Li, X. M. S., Ewing-Cobbs, L., Dennis, M., ... Swank, P. (2008). Prediction of cognitive sequelae based on abnormal computed tomography findings in children following mild traumatic brain injury. Journal of Neurosurgery Pediatrics, 1(6), 461-470. http://dx.doi.org/10.3171/PED/2008/1/6/461

Lori, S., Portaccio, E., Zipoli, V., Giannini, M., Scarpelli, S., Goretti, B., \& Amato, M. P. (2011). Cognitive impairment and event-related potentials in paediatric multiple sclerosis: 2-year study. Neurological Sciences, 32(6), 1043-1046. http://dx.doi.org/ 10.1007/s10072-011-0602-8

Madan, P., Kalra, O. P., Agarwal, S., \& Tandon, O. P. (2007). Cognitive impairment in chronic kidney disease. Nephrology Dialisis Transplantation, 22(2), 440-444. http://dx.doi.org/ 10.1093/ndt/gfl572

McAllister, T. W., Sparling, M. B., Flashman, L. A., Guerin, S. J., Mamourian, A. C., \& Saykin, A. J. (2001). Differential working memory load effects after mild traumatic brain injury. Neuroimage, 14(5), 1004-1012. http://dx.doi.org//10.1006/nimg.2001.0899

McKinlay, A., Dalrymple-Alford, J. C., Horwood, L. J., \& Fergusson, D. M. (2002). Long term psychosocial outcomes after mild head injury in early childhood. Journal of Neurology, Neurosurgery \& Psychiatry, 73(3), 281-288. http://dx.doi.org/10.1136/jnnp.73.3.281

McKinlay, A., Grace, R., Horwood, J., Fergusson, D., \& MacFarlane, M. (2009). Adolescent psychiatric symptoms following preschool childhood mild traumatic brain injury: evidence from a birth cohort. Journal of Head Trauma Rehabilitation, 24(3), 221-227. http://dx.doi.org/ 10.1097/HTR.0b013e3181a40590

Moustafa, A. A., Sherman, S. J., \& Frank, M. J. (2008). A dopaminergic basis for working memory, learning and attentional shifting in Parkinsonism. Neuropsychologia, 46(13), 3144-3156. http://dx.doi.org/10.1016/j.neuropsychologia.2008.07.011

Oster, I., Shamdeen, G. M., Gottschling, S., Gortner, L., \& Meyer, S. (2010). Electroencephalogram in children with minor traumatic brain injury. Journal of paediatrics and child health, 46(7-8), 373-377. http://dx.doi: $10.1111 / \mathrm{j} .1440-1754.2010 .01754 . \mathrm{x}$

Ozen, L. J., \& Fernandes, M. A. (2012). Slowing down after a mild traumatic brain injury: A strategy to improve cognitive task performance? Archives of Clinical Neuropsychology, 27(1), 85-100. http://dx.doi.org/10.1093/arclin/acr087

Perlstein, W. M., \& Larson, M. J. (2011). Psychophysiology and brain imaging of cognition and affect following traumatic brain injury: An overview of the special issue. International Journal of Psychophysiology, 82(1), 1-3. http://dx.doi.org/10.1016/j.ijpsycho.2011.07.013

Polich, J. (2007). Updating P300: An integrative theory of P3a and P3b. Clinical Neurophysiology, 118(10), 2128-2148. http://dx.doi.org/10.1016/j.clinph.2007.04.019 
Potter, D. D., Jory, S. H., Bassett, M. R., Barrett, K., \& Mychalkiw, W. (2002). Effect of mild head injury on event-related potential correlates of Stroop task performance. Journal of the International Neuropsychological Society, 8(6), 828-837. http://dx.doi.org/10.1017.S1355617702860118

Rubia, K., Hyde, Z., Halari, R., Giampietro, V., \& Smith, A. (2010). Effects of age and sex on developmental neural networks of visual-spatial attention allocation. Neuroimage, 51(2), 817-827. http://dx.doi.org/10.1016/j.neuroimage.2010.02.058

Shaw, P., Kabani, N. J., Lerch, J. P., Eckstrand, K., Lenroot, R., Gogtay, N., ... Wise, S. P. (2008). Neurodevelopmental trajectories of the human cerebral cortex. Journal of Neuroscience, 28(14), 3586-3594. http://dx.doi.org/10.1523/JNEUROSCI.5309-07.2008

Sinopoli, K. J., \& Dennis, M. (2012). Inhibitory control after traumatic brain injury in children. International Journal of Developmental Neuroscience, 30(3), 207-215. http://dx.doi.org/10.1016/j.ijdevneu.2011.08.006

Solbakk, A., Reinvang, I., Neilsen, C., \& Sundet, K. (1999). ERP indicators of disturbed attention in mild closed head injury: A frontal lobe syndrome? Psychophysiology, 36(6), 802-817. http://dx.doi.org/10.1111/1469-8986.3660802

Strandburg, R. J., Marsh, J. T., Brown, W. S., Asarnow, R. F., Higa, J., Harper, R., \& Guthrie, D. (1996). Continuous-processing-related-event-related potentials in children with attention deficit hyperactivity disorder. Biological Psychiatry, 40(10), 964-980. http://dx.doi.org/10.1016/0006-3223(95)00545-5

Straube, E. R., Bischoff, N., Nisch, C., Sauer, H., \& Volz, H. P. (2002). Input dysfunction and beyond-an evaluation of CPT components. Schizophrenia Research, 54(1-2), 131-139. http://dx.doi.org/10.1016/S0920-9964(01)00360-7

Suchan, B., Pickenhagen, A., \& Daum, I. (2005). Effect of working memory on evaluation-related frontocentral negativity. Behavioral Brain Research, 160(2), 331-337. http://dx.doi.org/10.1016/j.bbr.2004.12.014

Sumiyoshi, T., Higuchi, Y., Kawasaki, Y., Matsui, M., Kato, K., Yuuki, H., ...Kurachi M. (2006). Electrical brain activity and response to olanzapine in schizophrenia: A study with LORETA images of P300. Progress in Neuropsychopharmacology \& Biological Psychiatry, 30(7), 1299-1303. http://dx.doi.org/10.1016/j.pnpbp.2006.04.028

Wechsler, D. (1997). Wechsler Adult Intelligence Scale (3rd ed.). New York: The Psychological Corporation.

\section{Copyrights}

Copyright for this article is retained by the author(s), with first publication rights granted to the journal.

This is an open-access article distributed under the terms and conditions of the Creative Commons Attribution license (http://creativecommons.org/licenses/by/3.0/). 